\title{
Improvement of Life After PVCR in Complete Paraplegic Patients with Posttraumatic Severe Kyphosis
}

\author{
Dogac KARAGUVEN 1 , I. Teoman BENLI ${ }^{2}$, Emre ACAROGLU ${ }^{3}$, Yunus ATICI ${ }^{4}$, Omer OZEL $^{2}$, Sinan BAHADIR \\ ${ }^{1}$ Ufuk University, Faculty of Medicine, Department of Orthopedics and Traumatology, Ankara, Turkey \\ ${ }^{2}$ Baskent University, Faculty of Medicine, Istanbul Hospital, Department of Orthopeadics and Traumatology, Istanbul, Turkey \\ ${ }^{3}$ Ankara Spine Center, Ankara, Turkey \\ ${ }^{4}$ Gebze Medical Park Hospital, Department of Orthopeadics and Traumatology, Kocaeli, Turkey \\ ${ }^{5}$ Amasya University, Faculty of Medicine, Department of Neurosurgery, Amasya, Turkey
}

Corresponding author: I. Teoman BENLI cutku@ada.net

\section{ABSTRACT}

AIM: To determine the effect of posterior vertebral column resection (PVCR) in patients with paraplegia by using the American Spinal Injury Association (ASIA) score and Scoliosis Research Society (SRS)-22 questionnaire.

MATERIAL and METHODS: Twelve patients with posttraumatic paraplegia and severe angular kyphosis $\left(>60^{\circ}\right)$ had undergone PVCR between 6-24 months after the trauma for severe pain, persistent vertebral instability and difficulty in adherence to rehabilitation. ASIA scores and SRS-22 questionnaire results obtained in the preoperative and postoperative periods, and the last control were statistically compared to assess the presence of any change.

RESULTS: The average age of twelve patients included in this study was $35.6 \pm 10.2(21-51)$ years. Female/male ratio was $2 / 10(20.0 \%)$. The mean follow-up duration was $50.3 \pm 17.6(24-86)$ months. None of the patients had additional changes in neuromonitoring records during surgery. The mean preoperative kyphotic angle of the patients was $66.58^{\circ} \pm 7.1^{\circ}\left(60^{\circ}-82^{\circ}\right)$ which decreased to $7.0^{\circ} \pm 5.4^{\circ}$ in the postoperative period $(p<0.05)$. The mean ASIA score, which was $43.3 \pm 5.1$ preoperatively, increased to $44.4 \pm 4.4$ in the postoperative period. The SRS-22 score, which was $2.4 \pm 0.3$ in the preoperative period, increased to $4.2 \pm 0.4$ in the early postoperative period. This increase was found to be statistically significant $(p<0.05)$. The SRS-22 score was $4.1 \pm 0.4$ at last follow-up and was not statistically different from the early postoperative value $(p>0.05)$.

CONCLUSION: In the light of these data, it can be stated that PVCR is a safe and reliable procedure in paraplegic patients with rigid posttraumatic kyphosis and increases patient satisfaction.

KEYWORDS: Posttraumatic kyphosis, Paraplegia, ASIA score, SRS-22 questionnaire, PVCR

\section{INTRODUCTION}

$\mathrm{T}$ There is no widely accepted classification and treatment algorithm for sagittal angular deformities secondary to posttraumatic kyphosis which occur as a result of neglected or insufficiently treated burst and distraction fractures $(1,2)$. Fractures may be neglected due to lack of adequate treatment facilities or more often, due to clinicians focusing on vital organs in the setting of multiple organ injuries which usually occur secondary to high energy traumas, and these neglected fractures may result in severe posttraumatic kyphosis in the long term (3). Spinal instability and pseudoarthrosis, which causes severe pain and loss of function, are the most important concerns in posttraumatic kyphosis and conservative treatment is not indicated in those patients (2).
Dogac KARAGUVEN (1) : 0000-0003-2360-3907

I. Teoman BENLI (D) : 0000-0002-1878-0653

Emre ACAROGLU (D) : 0000-0002-8163-2944 $\begin{array}{ll}\text { Yunus ATICI } & \text { (D) : 0000-0002-9661-4618 } \\ \text { Omer OZEL } & \text { (1) : 0000-0002-6859-017X } \\ \text { Sinan BAHADIR (1) : } 0000-0002-1037-5645\end{array}$ 
Some authors recommend anterior alone approach, such as anterior corpectomy or anterior stabilization for thoracolumbar burst fractures, especially if the "McCormick Fragmentation Score" is high, to avoid kyphotic deformities or failure of posterior instrumentations in the long run (4-6). Benli et al. has reported very successful results with anterior alone approach consisting of anterior vertebrectomy, anterior strut grafts, and anterior plates or double rods, especially in moderate $\left(30^{\circ}-\right.$ $60^{\circ}$ ) posttraumatic kyphosis (4).

Wedge osteotomies, also called Thomassen or Domaniç osteotomies, which regards the disc space and the vertebra corpus as the midpoint, has gained popularity in the surgical treatment of rigid and mild $\left(>30^{\circ}\right)$ kyphosis $(8,24,36)$. In kyphotic and scoliosis deformities, correction rates of $55-80 \%$ have been reported with wedge osteotomies (15,26-29).

Suk et al. has defined the posterior vertebral column resection (PVCR) technique and published their results in 2001 (34). PVCR has been used in rigid and severe scoliosis cases and significantly high rates of correction have been reported. However, there are few studies on the utilization of PVCR in posttraumatic kyphosis, which is a technique used more commonly in neurofibromatosis and congenital or posttuberculosis kyphosis (19).

For these reasons, this study aims to evaluate the clinical and radiologic results of PVCR and posterior segmental instrumentation utilized in the surgical treatment of 12 patients with severe posttraumatic kyphosis who suffer from severe pain, spinal instability, paraplegia and difficulty in adherence to rehabilitation. On the other hand, this study is the first of its kind in the literature as it has been performed on paraplegic posttraumatic patients.

Another endpoint of this study is to investigate the effect of PVCR on the neurological status (determined by ASIA scores) and patient reported outcomes (determined by SRS22 scores which evaluates pain, function, mental status, appearance, and satisfaction from treatment). This study is also unique since it is one of the few studies in the literature where clinical evaluation is performed using SRS-22 scores in PVCR performed for posttraumatic kyphosis.

\section{MATERIAL and METHODS}

This study (Project no: KA20/219) was approved by the Scientific Research Institutional Review Board (Approval number: 94603339-604.01.02/17474). Written informed consent has been obtained from all patients enrolled in this study.

\section{Patients}

This is a retrospective cohort study based on hospital records. Twelve patients with paraplegia had history of severe local kyphosis developed at least 6 months after trauma, who underwent PVCR procedures due to severe pain and difficulty in adherence to rehabilitation and followed-up at least 2 years were included in this study (Table I). For assessment, the new AO thoracolumbar fracture classification (AOC) was utilized, which was proposed by Vaccaro et al. in 2013, and was tested for reliability by Kepler et al. in $2016(16,39)$.
Eight $(66.7 \%)$ of 12 patients had traffic accidents, 2 (16.7\%) suffered from industrial accidents and 2 (16.7\%) fell from a height. Of $8(66.7 \%)$ male patients, $6(60 \%)$ had car accidents while $2(16.7 \%)$ had motorcycle accidents. Four of the 6 car accidents were pedestrians hit by a speeding car and the remaining two had intravehicular injuries (Table I).

One of the motorcycle accidents involved a 22 years old Kosovan male who fell down a 70 meters high viaduct and his left hand was jammed to the handlebar. He had an AOC Type-C fracture-dislocation at T7-T8 level. The patient had accompanying multiple rib fractures and a chest tube had been placed due to flail chest. He had further developed Acute Respiratory Distress Syndrome (ARDS), and needed a tracheotomy in Pristine. This patient was admitted to our hospital one year after the injury. He had paraplegia and hypoesthesia below T7 level (Figure 1A-F). The other motorcycle accident involved a 26 years old male who was thrown into the air when he hit a truck. The patient had intracranial bleeding and was operated in Bulgaria. He was admitted to our hospital 17 months after the injury since he could not cooperate with the rehabilitation program because of severe pain. He had an AOC Type-A4 burst fracture at T12 level and was paraplegic below.

One of the patients who fell from a height was a 51 years old Libyan woman who had jumped out of her house during a bombing at the Libyan civil war. She had an AOC Type-A4 L1 burst fracture. She was paraplegic and admitted to our hospital 10 months after the injury. The second patient was a 21 years old Ukrainian woman who attempted suicide by falling from a height. She had undergone posterior decompression alone in Kyiv and 14 months after the injury she was brought to our hospital by a relative of hers. She had an AOC Type-A4 burst fracture, was paraplegic below $\mathrm{T} 12$, and had an $82^{\circ}$ sagittal angular kyphosis in the preoperative period (Figure 2A-D).

Both (16.7\%) industrial accident patients were males. One of the patients worked in a scrap car recycling facility and was crushed by a 15-ton press. He had undergone an urgent splenectomy operation and had stayed in the intensive care unit for multiple rib fractures and haemo-pneumothorax for 20 days. Then, he was operated for bilateral diaphyseal femur fractures. He was paraplegic at discharge from the intensive care unit and had an AOC Type-A4 fracture with complete fracture of the posterior elements at L1 level. The other industrial accident patient was a shipyard worker and fell onto the concrete floor when the rope he was hanging from broke while he was painting the exterior of a ship. He had an AOC Type-B2 distraction fracture at T9 vertebra and had undergone splenectomy due to intra-abdominal bleeding and burr hole decompression to relieve the increased intracranial pressure. He had stayed in the intensive care unit for approximately four months. The patient was brought to our hospital due to vertebral instability six months after the accident and was paraplegic below the T9 level.

A detailed preoperative history was obtained from the patients. The Turkish adaptation of SRS-22, which has been validated by Alanay et al. was utilized to assess patients (1). Following the preoperative systemic and neurological examination, the 


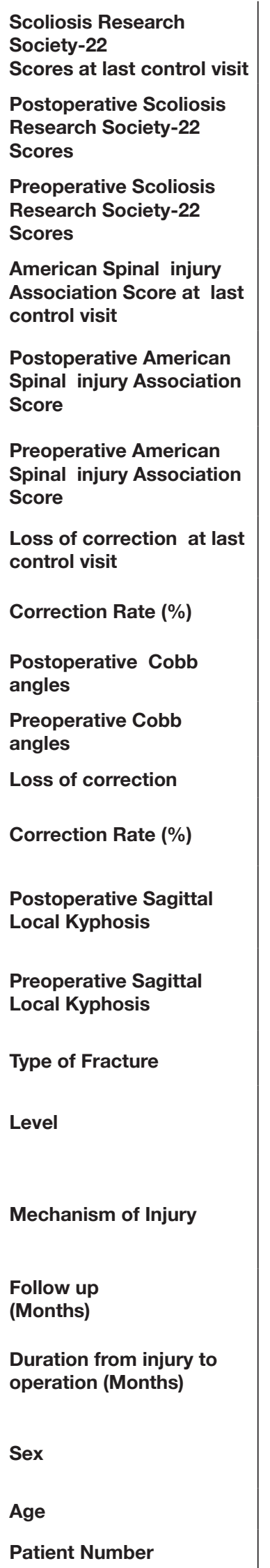

\begin{tabular}{|c|c|c|c|c|c|c|c|c|c|c|c|}
\hline مִ & $\nabla$ & 0 & $\tau$ & 0 & $\infty$. & ?ִ & مـا & 0 & $\nabla$ & ما & $\nabla$ \\
\hline$\dot{\nabla}$ & $\dot{\nabla}$ & लं & $\dot{\sigma}^{\circ}$ & $\dot{+}$ & $\dot{m}$ & $\dot{\nabla}$ & लं & $\dot{\nabla}$ & $\dot{\nabla}$ & $\dot{0}$ & $\dot{+}$ \\
\hline$\stackrel{\bullet}{\bullet}$ & مִ & 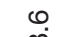 & ฯ & $\varphi$ & $\infty$ & $\varphi$ & $\varphi$ & ฯ & $\nabla$. & $\bullet$ & $\varphi$ \\
\hline & & & & & & & & & & & \\
\hline$\stackrel{\text { ì }}{\stackrel{⿰}{*}}$ & $\hat{\sim}$ & $\stackrel{\sim}{\sim}$ & خ̀ & זे & . & זे & 임 & זे & $\underset{\sim}{~}$ & ח & 움 \\
\hline ᄂ? & $\stackrel{\infty}{\underset{\sim}{4}}$ & ষ & テ & g & f & $\mathscr{q}$ & g & প & g & $\stackrel{\infty}{\infty}$ & $\mathscr{ల}$ \\
\hline$\stackrel{\text { L }}{q}$ & $\stackrel{\infty}{+}$ & $\underset{\forall}{\forall}$ & $\stackrel{\sim}{\forall}$ & $\stackrel{\infty}{+}$ & $\stackrel{\varphi}{\forall}$ & $\stackrel{\llcorner}{\sim}$ & $\stackrel{\infty}{+}$ & $\stackrel{\infty}{+}$ & $\stackrel{\sim}{\forall}$ & $\stackrel{\infty}{\infty}$ & স্ \\
\hline ষ & $\stackrel{\infty}{+}$ & テ & F & $\stackrel{\infty}{+}$ & $\mathscr{q}$ & ষ & $\stackrel{\infty}{+}$ & $\stackrel{\infty}{+}$ & $\stackrel{\sim}{\forall}$ & @) & ల్ \\
\hline$\stackrel{\circ}{\sim}$ & $\stackrel{\circ}{\circ}$ & $\circ$ & $\stackrel{\circ}{\sim}$ & $\stackrel{\circ}{\sim}$ & $\stackrel{\circ}{\sim}$ & $\stackrel{\circ}{\sim}$ & $\stackrel{\circ}{\sim}$ & $\circ$ & $\stackrel{\circ}{\circ}$ & 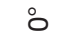 & $\stackrel{\circ}{\circ}$ \\
\hline $\begin{array}{l}\mathscr{\infty} \\
\ddot{\infty}\end{array}$ & Б் & 음 & 闺 & م & 유 & ¿ & $\stackrel{\sim}{N}$ & 음 & 음 & $\infty$ & 으 \\
\hline$\stackrel{\circ}{\circ}$ & $\stackrel{\circ}{\sim}$ & $\stackrel{\circ}{\circ}$ & $\stackrel{\circ}{+}$ & $\stackrel{\circ}{\circ}$ & $\stackrel{\infty}{\infty}$ & $\infty$ & $\stackrel{\circ}{\forall}$ & $\stackrel{\circ}{\circ}$ & $\stackrel{\circ}{\circ}$ & $\stackrel{\circ}{\forall}$ & $\therefore$ \\
\hline$\stackrel{\circ}{\sim}$ & 㐫 & $\stackrel{\circ}{\sim}$ & $\stackrel{\circ}{\stackrel{\infty}{\sim}}$ & $\stackrel{\circ}{\circ}$ & $\stackrel{\circ}{\circ}$ & $\stackrel{\circ}{\stackrel{N}{ }}$ & $\stackrel{\circ}{\circ}$ & $\stackrel{\circ}{\underset{\leftarrow}{\top}}$ & $\stackrel{\infty}{\infty}$ & $\stackrel{\circ}{N}$ & 음 \\
\hline ஓं & $\stackrel{\circ}{\leftarrow}$ & in & $\stackrel{\circ}{\circ}$ & $\stackrel{\circ}{\sim}$ & $\stackrel{\circ}{m}$ & $\stackrel{\circ}{\sim}$ & $\stackrel{\circ}{\sim}$ & $\stackrel{\circ}{\sim}$ & $\stackrel{\circ}{\forall}$ & in & $\stackrel{\circ}{\circ}$ \\
\hline 옹 & $\begin{array}{l}\text { m } \\
\text { ๙் }\end{array}$ & $\begin{array}{l}\text { の } \\
\text { ल) }\end{array}$ & $\begin{array}{l}\infty \\
\text { ஸ் }\end{array}$ & 오 & ๙̄ं & $\underset{\infty}{\Gamma}$ & $\begin{array}{l}+ \\
\infty\end{array}$ & $\begin{array}{l}0 \\
\text { ๙் }\end{array}$ & $\begin{array}{l}\infty \\
\infty \\
\infty\end{array}$ & 우 & $\hat{\mathscr{\theta}}$ \\
\hline ¿ & مْ & 음 & $\stackrel{\circ}{\forall}$ & ○ & ¿ & $\infty$ & $\stackrel{\circ}{\sim}$ & in & $\stackrel{\circ}{\infty}$ & ○ & $\stackrel{\sim}{\sim}$ \\
\hline ¿̊ & 용 & ণ్రి & 용 & :̊ & $\stackrel{0}{\sim}$ & ণ్రి & § & $\stackrel{0}{0}$ & $\stackrel{N}{N}$ & $\begin{array}{l}\circ \\
0\end{array}$ & :̊ \\
\hline$\underset{\substack{+\\
}}{+}$ & $\underset{⿱ 亠 䒑}{+}$ & 0 & $\underset{⿱ 亠 䒑}{+}$ & $\underset{⿱ 亠 䒑}{+}$ & $\underset{⿱ 亠 䒑}{+}$ & $\underset{⿱ 亠 䒑}{4}$ & $\underset{⿱ 亠 䒑}{+}$ & $\begin{array}{l}\text { ⿵̀ } \\
\text { n. }\end{array}$ & ஸे & $\underset{⿱ 亠 䒑}{+}$ & 0 \\
\hline 5 & 更 & 둥 & $\stackrel{N}{F}$ & $\stackrel{\sim}{\leftarrow}$ & J & 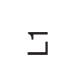 & $\frac{\sim}{\Gamma}$ & $\underset{1}{\Gamma}$ & $\stackrel{\stackrel{P}{1}}{1}$ & $\frac{\sim}{\perp}$ & $\begin{array}{l}\stackrel{\infty}{1} \\
\stackrel{1}{\leftarrow}\end{array}$ \\
\hline 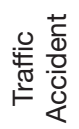 & 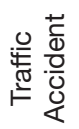 & 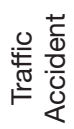 & 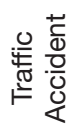 & 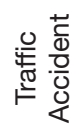 & 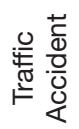 & 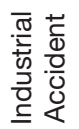 & 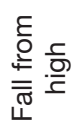 & 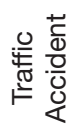 & 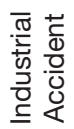 & 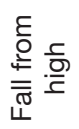 & 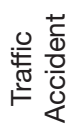 \\
\hline $\mathscr{\bullet}$ & $\widetilde{\mho}$ & م & 䓃 & న్ & f & $\mathscr{P}$ & $\stackrel{\infty}{+}$ & $\stackrel{\infty}{\infty}$ & $\stackrel{\Delta}{\sim}$ & 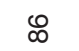 & $\stackrel{d}{N}$ \\
\hline$\stackrel{\simeq}{\sim}$ & $\Lambda$ & $\infty$ & 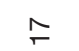 & $\sigma$ & $\stackrel{+}{N}$ & $\infty$ & $\underset{\leftarrow}{\nabla}$ & స & $\bullet$ & 으 & $\stackrel{\simeq}{\simeq}$ \\
\hline$\frac{\frac{0}{\pi}}{\sum^{\frac{\pi}{2}}}$ & $\frac{\frac{0}{\pi}}{\sum}$ & $\frac{0}{\frac{\pi}{\pi}}$ & $\frac{\frac{0}{\pi}}{\sum}$ & $\frac{\frac{0}{\pi}}{\sum}$ & $\frac{\frac{0}{\pi}}{\sum}$ & $\frac{\frac{0}{\pi}}{\sum}$ & $\frac{\stackrel{\oplus}{\widetilde{N}}}{\frac{\mathbb{\Phi}}{0}}$ & $\frac{\frac{0}{\pi}}{\sum}$ & $\frac{\frac{\omega}{\pi}}{\sum}$ & $\frac{\stackrel{\oplus}{\widetilde{N}}}{\frac{\mathbb{\Phi}}{0}}$ & $\frac{\frac{0}{\pi}}{\sum}$ \\
\hline$\stackrel{\text { م }}{q}$ & స్ల & ষ & $\stackrel{\mathscr{N}}{ }$ & ల్ల & $\stackrel{्}{~}$ & ఫ & $\bar{\sim}$ & $\stackrel{\infty}{\sim}$ & $\stackrel{\infty}{+}$ & 5 & N \\
\hline . & $\sim$ & m & $\nabla$ & مـ & 0 & $\wedge$ & $\infty$ & $a$ & 음 & $\mp$ & $\simeq$ \\
\hline
\end{tabular}




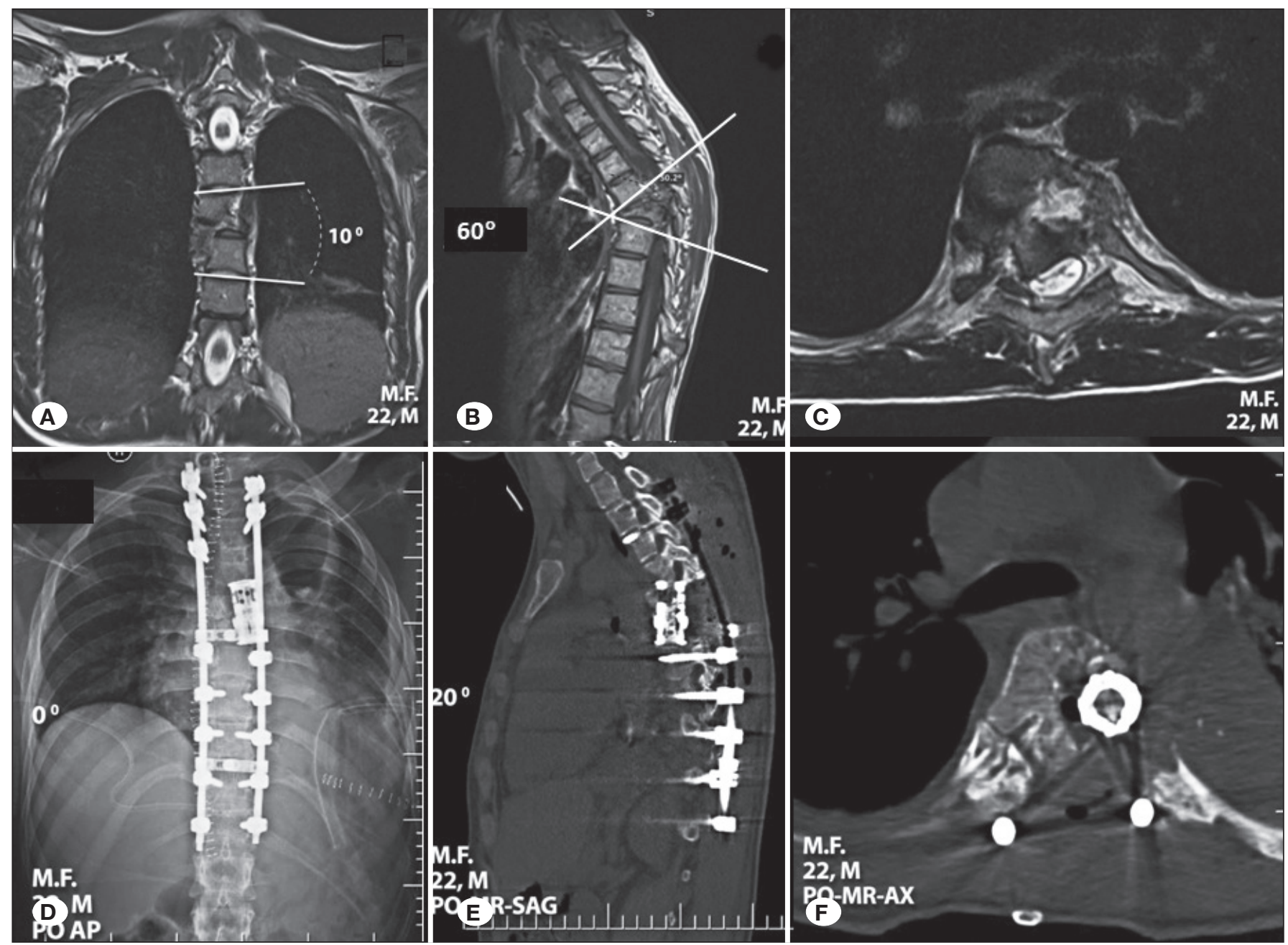

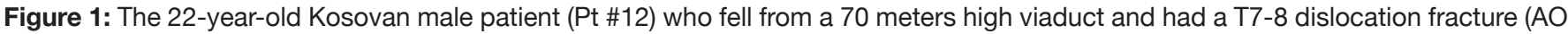
type C). A) Coronal MRI, B) sagittal MRI, and C) axial MRI scans, and postoperative D) anteroposterior X-ray, E) lateral X-ray, F) axial MRI scan.
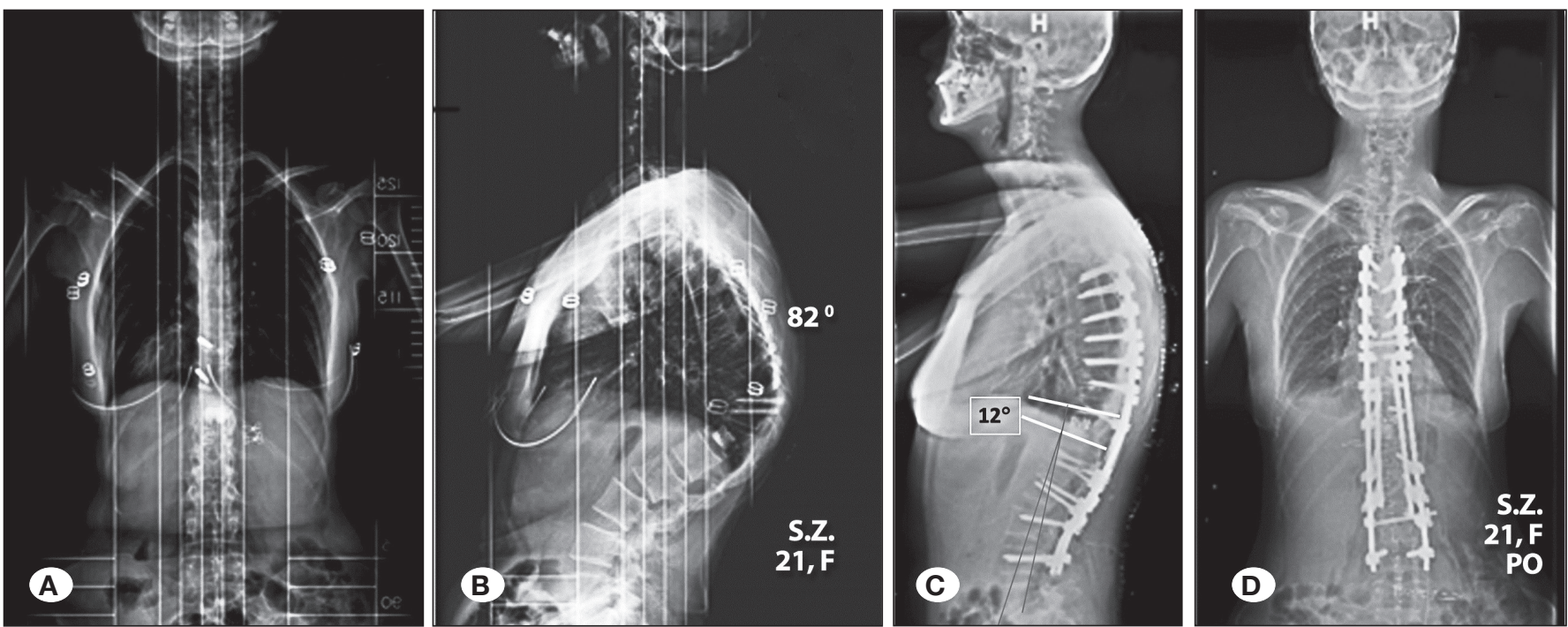

Figure 2: The 21-year-old paraplegic Ukrainian patient ( $\mathrm{Pt} \mathrm{\# 8)} \mathrm{who} \mathrm{had} \mathrm{jumped} \mathrm{from} \mathrm{a} \mathrm{height} \mathrm{and} \mathrm{had} \mathrm{an} \mathrm{AO} \mathrm{type} \mathrm{A4} \mathrm{T12} \mathrm{burst} \mathrm{fracture}$ with an $82^{\circ}$ posttraumatic kyphosis. Preoperative A) anteroposterior (AP), B) lateral, and postoperative C) AP, and D) lateral X-rays are shown. The correction rate for the angle of kyphosis was $85,4 \%$. 
ASIA scores were determined. Routine laboratory tests, $X$-rays, computerized tomography (CT), and magnetic resonance imaging (MRI) scans were obtained. Sagittal angular kyphosis and Cobb angles of scoliosis deformities, if present, were measured on the x-rays. The status of vertebral structures, presence of subluxation, neural injury, and the status of foramina and the spinal canal was determined in sagittal, coronal, and axial planes on CT and MRI scans. The patients were taken into operation following appropriate consultations.

\section{Surgical Technique}

The patients were placed in prone position under general anesthesia. After positioning, appropriate coils and electrodes for motor evoked potentials (MEP), somatosensory evoked potentials (SSEP) and electromyography (EMG) were placed in muscles and scalp. As standard preoperative measurements were obtained, neural monitoring was performed both preoperatively and intraoperatively. The main reason for neuromonitorization was to prevent any additional damage on the existing deficit since the operation was performed on a higher level and to evaluate any possible neurological improvement in the intraoperative or the postoperative period.

A midline incision was performed centering the sagittal angular kyphosis and the vertebrae between the uppermost and the lowest instrumented vertebrae were exposed. Temporary transpedicular polyaxial titanium screws and rods were placed one level above and one level below the kyphotic region. If this was not possible, they were placed on the next suitable vertebrae (second or third) and intraoperative stability to the vertebral column was achieved. Spinal nerve roots were found and preserved following posterior decompression. The spinal cord was checked for integrity. Then PVCR was performed at minimum 1 and maximum 2 vertebrae (Figure 3A-D).

In patients with scoliosis, the resection was carried out at the apex of the scoliosis deformity by approaching from the convex side. In patients without scoliosis, the vertebrae which corresponds to the narrowest spinal canal segment(s) or foramina level(s) was removed.

Upon resection of the vertebrae, permanent screws and rods were placed one by one and in-situ compression was performed at a ratio determined preoperatively to correct the sagittal angular kyphosis. The coronal deformity was corrected simultaneously. For anterior fusion at the resection level, either a tricortical autograft prepared from the iliac crest or a titanium cage was implemented (Figure 4). A suction drain was placed and the surgical wound was closed layer by layer.

Throughout the operation combined neuromonitoring consisting of MEP, SSEP, and EMG was performed and recorded. Intraoperative blood loss was also noted.

Postoperatively, X-rays were obtained and the Cobb angle measurements of kyphosis and scoliosis were performed and compared to the preoperative values. At the time of final follow-up, any loss of surgical correction in sagittal and
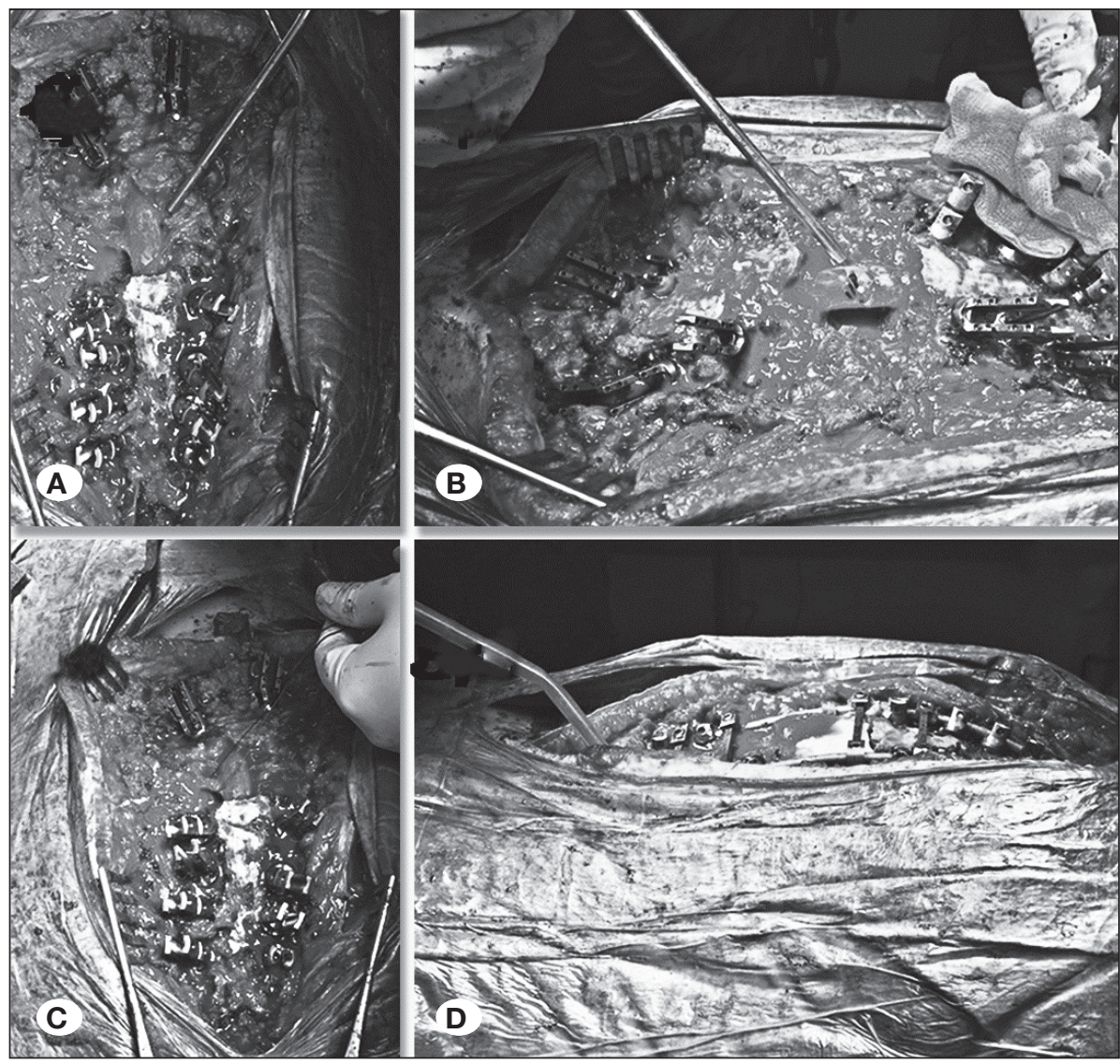

Figure 3: PVCR technique A, B)

following the excision of the posterior elements, wide decompression, and the transpedicular screw fixation.

C) Spinal cord following the excision of the anterior column. D) Following anterior strut graft or autologous graft placement, rod placement and appropriate posterior decompression. 
coronal planes was evaluated by using X-ray images. Also, ASIA and SRS-22 scores at the final follow-up were compared to the preoperative scores.

\section{Statistical Analysis}

The SPSS 25.0 program was used in the statistical analyses. To compare preoperative and postoperative parameters the student t-test was used. The value of probability was set as $p=0.05$.

\section{RESULTS}

The average age of twelve patients included in this study was $35.6 \pm 10.2(21-51)$ years. Female/male ratio was $2 / 10(20.0 \%)$. The mean follow-up duration was $50.3 \pm 17.6$ (24-86) months. The mean interval between the injury and the operation was $12.4 \pm 5.9$ (6-24) months (Table II).

When the spinal fracture and fracture-dislocation levels leading to paraplegia were examined, the thoracolumbar region was the most frequently affected segment. 9 (75\%) patients had a total of 12 vertebral injuries in this region (Table I). Of these 9 patients, 7 (58.3\%) had Type-A4 burst fractures while 2 $(16.7 \%)$ had type-B2 distraction fractures according to the AOC. In the thoracic region, two Type-C fracture-dislocations at T7-T8 and T10-T11 levels and one Type-B2 distraction fracture at T9 level (Table I) were observed. In this study, no PVCR procedure was performed in the lumbar region (Figure 4, 5).

No electrophysiological change was observed in the SEP, MEP, and EMG recordings throughout any operation. The average amount of intraoperative bleeding was $1499 \pm 244 \mathrm{ml}$, and $4.6 \pm 1.1$ units of erythrocyte suspension were transfused. There was a slight drop in postoperative hematocrit levels compared to preoperative levels of $37.9 \pm 4.7 \mathrm{mg} / \mathrm{ml}$, but this was not statistically significant ( $p>0.05)$. There was no local or systemic complication in the postoperative period and during the follow-up.

The local kyphosis angle which was $66.5^{\circ} \pm 7.1^{\circ}$ (Range: $60^{\circ}-$ $82^{\circ}$ ) in the preoperative period, had improved to $7.0^{\circ} \pm 5.4^{\circ}$ (Range: $\left.0^{\circ}-20^{\circ}\right) \quad(p<0.05)$ postoperatively with a correction rate of $89.4 \pm 8.7 \%$ (Range: $66.7 \%^{\circ}-100 \%$ ) following PVCR, anterior fusion with strut grafts and posterior segmental instrumentation. There was an $81.2 \pm 20.8 \%$ improvement in the scoliosis deformity accompanied by kyphosis, which was statistically significant. At last follow-up, there was minimal loss of correction with $2.5^{\circ} \pm 1.7^{\circ}$ and $1.7^{\circ} \pm 1.0^{\circ}$ in angular kyphosis and scoliosis deformity, respectively (Table II).

All patients were ASIA-A type in the preoperative period. The mean score was $43.3 \pm 5.1$ in the preoperative period, which increased to $44.4 \pm 4.4$ postoperatively. As of last followup, the mean ASIA score was $44.7 \pm 4.3$. Although this mild increase in the ASIA score in the postoperative period and at the last control was not statistically significant $(p>0.05)$, patients reported an improvement in the sensory level and iliopsoas muscle control (Table II).

The SRS-22 score, which evaluates pain, function, mental status, appearance, and satisfaction over a score of 5 ,

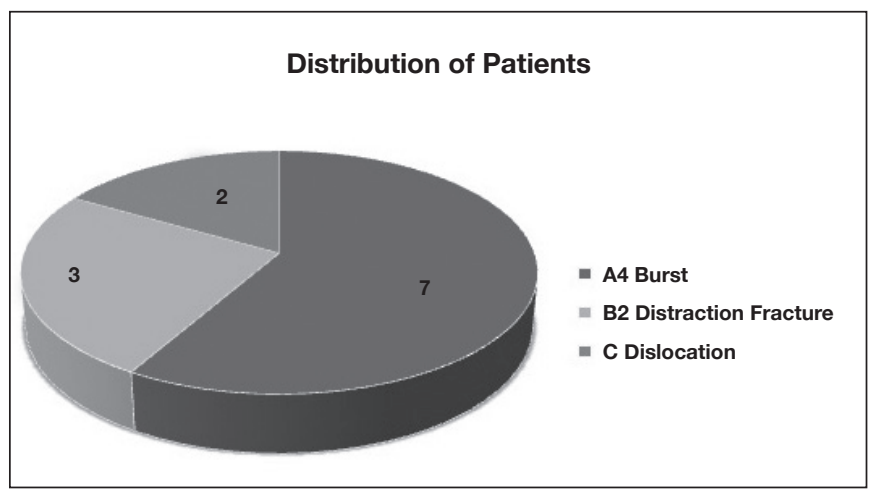

Figure 4: Distribution of AO classification based on fracture types.

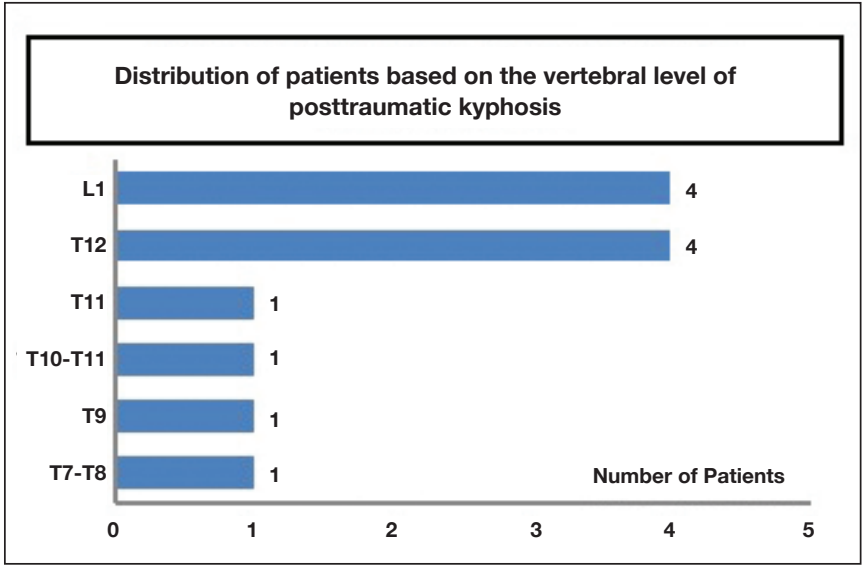

Figure 5: Distribution of patients based on the vertebral level of posttraumatic kyphosis.

increased to $4.2 \pm 0.4$ from $2.4 \pm 0.3$, which was statistically significant $(p<0.05)$. The mean SRS-22 scores at the last control $(4.1 \pm 0.4)$ was not significantly different from the postoperative scores $(p>0.05)$ (Table II).

In patients who began rehabilitation, in-bed exercises were more effective since the patients could lie on their backs and sit. Time spent at the tilt table and robotic rehabilitation had increased. Although this increase could not be recorded, the observations of the physiotherapists confirmed this notion (Figure 6, 7).

\section{DISCUSSION}

Each year, millions of vertebral fractures occur in the world secondary to traffic accidents, industrial injuries, falls from heights, sports injuries, or crush injuries and nearly $20 \%$ of these patients suffer from spinal cord injury. Although substantial progress has been made in understanding the mechanism, biomechanical features, diagnosis, and treatment of these injuries, they are still a major point of concern for spinal surgeons as a serious social and economic problem (23). Ninety percent of vertebral fractures involve the thoracic and lumbar vertebrae. The Thoracolumbar Injury Classification and Severity Score (TLICS) proposed by the Spine Trauma Study Group is a treatment algorithm that has been tested for reliability and accepted globally $(6,38)$. According to the 
Table II: Mean Preoperative, Postoperative and at the Last Control Visit Kyphosis Angles, Deformity on Coronal Plane Angles, American Spinal Injury Association Scores, Scoliosis Research Society-22 Scores

Number of patients

Age: Mean \pm Standart Deviation (Range)

Sex: Female / Male

Time between the injury and the operation (months): Mean \pm Standart Deviation (Range)

Postoperative follow-up (months): Mean \pm Standart Deviation (Range)

(a) Preoperative sagittal angular kyphosis angles: Mean \pm Standart Deviation (Range)

(b) Postoperative sagittal angular kyphosis angles: Mean \pm Standart Deviation (Range)

$\mathrm{p}$ (Paired t-test : a-b)

Postoperative sagittal angular kyphosis correction: Mean \pm Standart Deviation (Range)

Loss of correction in sagittal angular kyphosis at the last control: Mean \pm Standart Deviation (Range)

(a) Preoperative Cobb angle of the scoliosis deformity in the coronal plane: Mean \pm Standart Deviation (Range)

(b) Postoperative Cobb angle of the scoliosis deformity in the coronal plane: Mean \pm Standart Deviation (Range)

p (Paired t-test : a-b)

Rate of postoperative correction in the Cobb angle of the scoliosis deformity in the coronal plane: Mean \pm Standart Deviation (Range)

Loss of correction in the Cobb angle of the scoliosis deformity in the coronal plane at the last control: Mean \pm Standart Deviation (Range)

(a) Preoperative American Spinal Injury Association score : Mean \pm Standart Deviation (Range)

(b) Postoperative American Spinal Injury Association score : Mean \pm Standart Deviation (Range)

$\mathrm{p}$ (Paired t-test : a-b)

$0.067(p>0.05)$

(c) American Spinal Injury Association score at the last control: Mean \pm Standart Deviation (Range)

p (Paired t-test : a-c)

$44.7 \pm 4.3(36-49)$

$0.67(p>0.05)$

(a) Preoperative Scoliosis Research Society-22 questionnaire result : Mean \pm Standart Deviation (Range)

(b) Postoperative Scoliosis Research Society-22 questionnaire result : Mean \pm Standart Deviation (Range)

p (Paired t-test : a-b)

(c) Scoliosis Research Society-22 questionnaire result at the last control: Mean \pm Standart Deviation (Range)

p (Paired t-test : a-c)

$$
2.4 \pm 0.3(1.8-3)
$$

$4.2 \pm 0.43(3.6-4.3)$

\section{$0.00(p<0.05)$}

$4.1 \pm 0.4(3.5-4.6)$

$0.083(p>0.05)$
TLICS, instability and accompanying neurological deficits are accepted as indications for surgery. The failure of the posterior ligamentous complex which prevents posterior kyphosis is also emphasized by the TLICS (38).
Burst fractures, especially those in the thoracolumbar region, may cause posttraumatic kyphosis if they are not surgically treated indication $(5,9,20,39,40)$. The "Fragmentation Score", proposed by McCormack et al., is directly related to the severity and the force of injury. In burst fractures, post- 

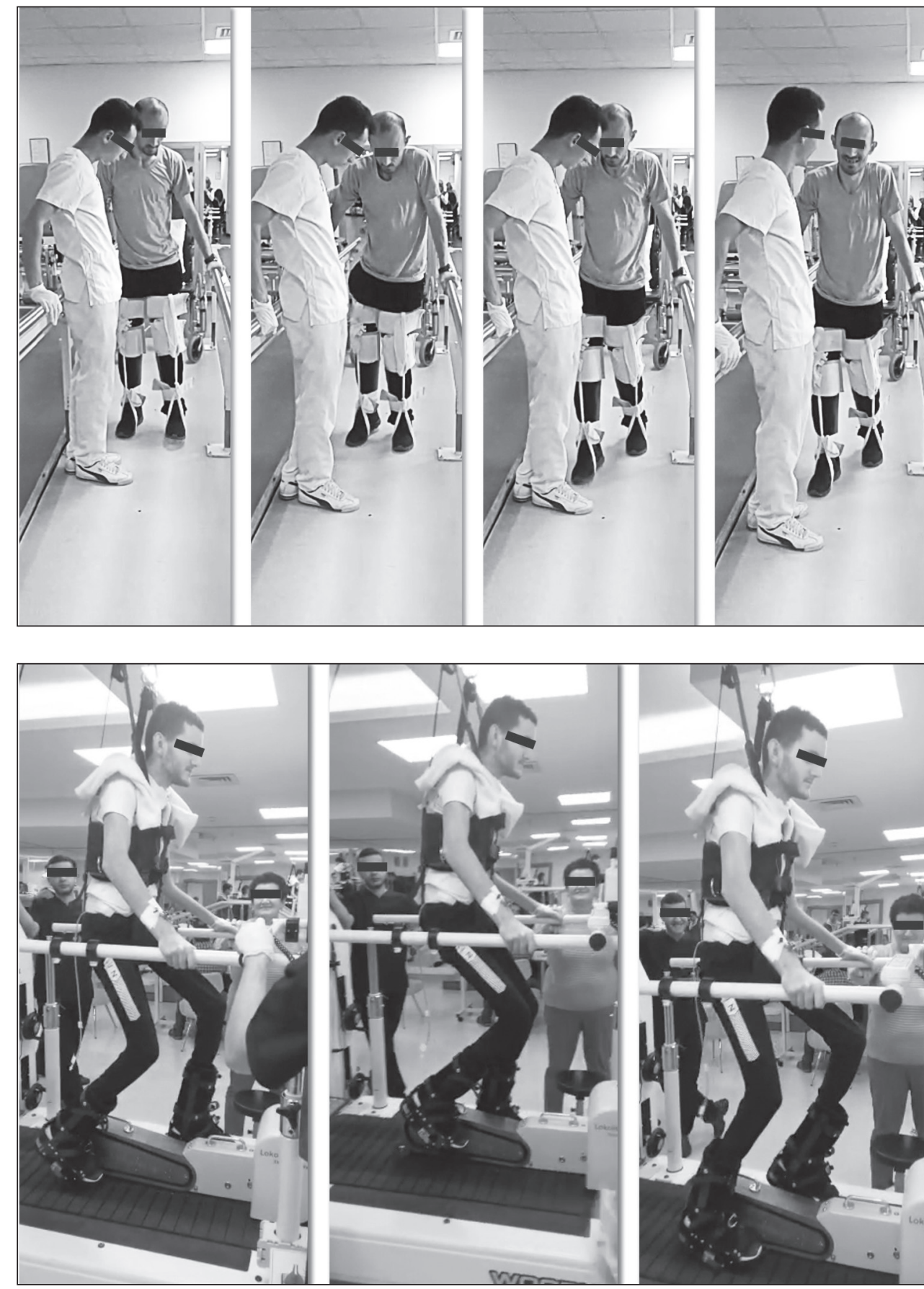

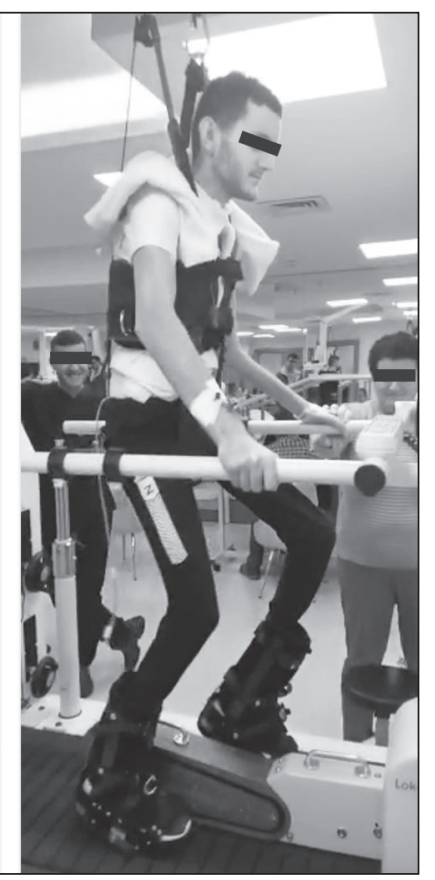

Figure 6: The paraplegic patient who was crushed under 15 tons (Pt\#7) and had an AO type A-4 burst fracture at $L 1,2$ during walking exercise on the parallel bar in the follow up period.
Figure 7: The patient shown in Figure 3 (Pt \#12) on the robotic walking device was seen. traumatic progressive collapse of vertebra accompanied by kyphosis occurs secondary to the lack of sufficient support in the anterior part of the vertebral column $(4,5,9,20,21,42)$. Posttraumatic kyphosis, as in our patients, is most frequently located in the thoracolumbar region (40). Mixing of disc and soft tissue fragments with bone fragments have been blamed in the process of pseudoarthrosis in AO Type-A4 burst fractures where posttraumatic kyphosis is common $(22,40)$. On the other hand, neglecting or missing a vertebral fracture in patients suffering from severe multiple trauma and paraplegia can also lead to posttraumatic kyphosis as was the case in our study. Nine $(75 \%)$ of our patients were such patients who received no treatment for spinal injury initially. The mean time between trauma and operation was $12.4 \pm 5.9$ months in our study. Implant failures such as screw pull-outs, rod fractures in case of posterior instrumentations that are not long enough and pseudoarthrosis can also result in posttraumatic kyphosis (41). Three patients in our study had undergone posterior instrumentation alone at the time of injury although they had Type-A4 fractures and those patients developed posttraumatic kyphosis accompanied by implant failure during follow-up. 
Posttraumatic kyphosis should be treated surgically $(22,29,40)$. However, it has been shown that kyphotic deformities less than $30^{\circ}$ do not cause serious problems. Follow up is sufficient in these patients provided that there are no neurologic deficits. In case of spinal stenosis, posterior decompression and/or posterior instrumentation is advised (29).

Similar to thoracolumbar burst fractures with high acute fragmentation scores, the most frequently utilized technique in patients with posttraumatic kyphosis is used to be anterior corpectomy followed by posterior instrumentation. Our practice in the past consisted of anterior vertebrectomy and anterior instrumentation by an anterior approach in cases with $30^{\circ}-60^{\circ}$ posttraumatic kyphosis (5). In recent years, numerous studies comparing single step, simultaneous, subsequent, or two-step application of several techniques, including anterior corpectomy with the anterior approach and posterior instrumentation, were published $(17,30,37,45)$.

For correction of mild $\left(0^{0}-30^{\circ}\right)$ kyphosis, the Smith Peterson osteotomy, where compression is performed via posterior instrumentation, is a successful technique and has been proven to be effective, especially in children who have an elastic anterior disc space $(31,32)$. All kyphotic deformities between $30^{\circ}$ and $60^{\circ}$ can be successfully treated with wedge osteotomies $(8,11,30)$. However, for the patients with posttraumatic kyphosis more than $60^{\circ}$, there is no recommended specific surgical technique in the literature. For this reason, in our study, we evaluated patients with posttraumatic kyphosis more than $60^{\circ}$. PVCR was performed on 12 paraplegic patients (mean age $35.6 \pm 10.2$ years), two females and ten males. All patients were ASIA-A. Three patients had thoracic fractures while 9 patients had thoracolumbar fractures.

PVCR had been first defined in severe rigid scoliosis deformities in 2001 by Suk et al. (34). Significant amount of correction in both planes has been reported by studies evaluating its use in kyphoscoliosis, congenital kyphosis, kyphosis secondary to neurofibromatosis, fused spondyloptosis and posttuberculosis kyphosis $(2,10,12,21,25,28,33,35,43,44)$.

The mean follow-up duration in our study was $50.3 \pm 17.6$ (2486) months after PVCR. Our study showed that PVCR provided significant correction rates both in the sagittal and the coronal planes $(p<0,05)$. Preoperative sagittal local kyphosis, which was $66.5^{\circ} \pm 7.1^{\circ}$ (Range: $60^{\circ}-82^{\circ}$ ), had improved to $7.0^{\circ} \pm 5.4^{\circ}$ (Range: $0^{\circ}-20^{\circ}$ ) in the postoperative period with $89.4 \% \pm 8.7 \%$ (Range: $66.7 \%-100 \%$ ), correction rate as a result of PVCR, anterior fusion/cage implementation and posterior segmental instrumentation. At the last control, there was minimal loss of correction in sagittal angular kyphosis and scoliosis deformity $\left(2.5^{\circ} \pm 1.7^{0}\right.$ and $1.7^{\circ} \pm 1.0^{\circ}$, respectively $)$.

Serious intra-operative bleeding, hypovolemic, cardiac, thrombotic, and neurologic complications have been reported during PVCR $(2,10,13,25,35,44)$. Aydınlı et al. have reported an estimated blood loss of $1072 \mathrm{ml}, 39 \%$ of which occurred during the vertebrectomy stage in their study on 20-patient series with PVCR (3). Wang et al. have reported a $22.9 \%$ rate of respiratory and cardiovascular complications in their study on non-neurological complications of PVCR (43). In our study, the average intraoperative bleeding was $1499 \pm$ $244 \mathrm{ml}$ and $4.6 \pm 1.1$ units of erythrocytes were transfused. There was a slight drop in the hematocrit, which was 37.9 $\pm 4.7 \mathrm{mg} / \mathrm{ml}$ in the preoperative period, however, this was not statistically significant $(p>0.05)$. There was no local or systemic complication in the perioperative period or during follow-up. The reason for the absence of additional systemic or local complications can be explained by the fact that none of the patients had comorbidities and all 12 patients were younger than 60 of which $33.3 \%$ (4 patients) were between $20-30$ and $25 \%$ ( 3 patients) were between $30-40$ years of age. Moreover, intraoperative close hemodynamic monitorization, neuromonitorization and the fact that the surgical team had completed the learning curve have also contributed.

Injury to the spinal cord or the nerve roots is one of the most important complications of PVCR. Sui et al. have reported spinal cord injury in 1 of 27 PVCR cases and stated that neural intra-operative monitoring helps reduce the neural complication risk (33). Atici et al. have reported 2 cases of neurological deficit out of 17 patients in 2017 (2). Cho et al. and Huang et al. state that neural intra-operative monitoring application decreases neurological injury risk based on their 90 and 82 patient case series, respectively $(7,14)$. We have used neural intra-operative monitoring routinely and observed no exacerbation of the preoperatively existing neurologic status. The main rationale behind neuromonitorization is to avoid any additional neurological damage during PVCR since the operation is performed above the level of original injury. On the other hand, this neuromonitorization aids in detecting a possible neurological recovery during or after the operation. PVCR is performed to prevent any neurological exacerbation caused by the strain and compression of the spinal cord due to kyphosis and any additional damage would be spiritually devastating for the patient.

Twelve patients in our study were paraplegic posttraumatic kyphosis patients who were ASIA-A. Although there was no statistically significant change between preoperative and postoperative ASIA scores ( $p>0.05)$, a slight improvement in their neurologic situation was observed. The preoperative ASIA score was $43.3 \pm 5.1$ which increased to $44.4 \pm 4.4$ postoperatively and was found to be $44.7 \pm 4.3$ at the last control. This improvement can be attributed to the patients regaining sensation in lower dermatomes and slight motor improvement in iliopsoas muscles. This mild improvement, observed postoperatively on the last control, which was not statistically significant but stated by the patients is believed to be a result of reduction of the tension on the spinal cord and the removal of spinal stenosis caused by the fragments in the spinal canal.

The SRS-22 score, which measures pain, function, mental status, appearance, and satisfaction from treatment, was calculated in the preoperative and postoperative period, as well as at the last control in our study. Few studies make this comparison in patients with angular kyphosis undergoing PVCR. In a multicenter study including 45 cases in 2015, Papadopoulos et al. reported that the preoperative SRS-22 
score of 3.18 and had increased to 3.54 postoperatively (25). Lee et al. report that despite a $35.3 \%$ reoperation rate, the SRS-22 score had increased to $3.4 \pm 0.8$ from $2.6 \pm 0.9$ in 34 cases (18). In our study, SRS-22 scores had increased from $2.4 \pm 0.3$ to $4.2 \pm 0.4$ in the postoperative period which was statistically significant $(p<0.05)$. The SRS-22 score was 4.1 \pm 0.3 at the last control and this score was not significantly different from the postoperative score $(p>0.05)$. This increase in SRS-22 scores can be explained by the improvement in appearance function, even though slightly in the latter, significant reduction in pain scores, and increased patient satisfaction due to surgery where no treatment had been provided except for two patients.

We also observed increased compliance with rehabilitation. The length of stay on the robotic walking device had increased and rehabilitation became more efficient.

\section{CONCLUSION}

This study shows that in patients with severe and rigid posttraumatic kyphosis suffering from severe pain, spinal instability, difficulty in cooperating to rehabilitation, and spinal instability, PVCR allows high correction rates in sagittal angular kyphosis with or without accompanying scoliosis. Although there were no statistically significant changes in the ASIA scores of the patients, a slight improvement in their neurological conditions were observed. Additionally, a statistically significant improvement was observed in the SRS-22 scores which evaluate pain, function, mental status, appearance, and satisfaction from the treatment. There were no local or systemic complications or deterioration in the neurological status in the postoperative period or at the last control. In the light of these data, it can be said that PVCR is an effective and safe technique in patients with severe and rigid posttraumatic kyphosis accompanied by paraplegia and it increases patient satisfaction.

\section{REFERENCES}

1. Alanay A, Cil A, Berk H, Acaroglu RE, Yazici M, Akcali O, Kosay C, Genc Y, Surat A: Reliability and validity of adapted Turkish Version of SRS-22 questionnaire. Spine (Phila Pa 1976) 30(21):2464-2468, 2005

2. Atici $Y$, Balioglu MB, Kargin D, Mert M, Albayrak A, Kaygusuz MA: Analysis of complications following PVCR for the treatment of severe angular kyphosis greater than $100^{\circ}$. Acta Orthop Traumatol Turc 251(3):201-208, 2017

3. Aydinli U, Kara K, Mutlu M, Osman Yaray O: Results of PVCR: Surgical modification of Suk technique. Global Spine J 8(5): 478-482, 2018

4. Benli IT, Guclu B, Kaya A, Karaguven D: The evaluation of fragmantation scores of the posttraumatic kyphosis patients treated by surgically. J Turk Spinal Surg 19:97-109, 2008

5. Benli IT, Kaya A, Uruç V, Akalin S: Minimum 5-year followup surgical results of post-traumatic thoracic and lumbar kyphosis treated with anterior instrumentation: Comparison of anterior plate and dual rod systems. Spine (Phila Pa 1976). 32(9):986-994, 2007
6. Bono CM, Vaccaro AR, Hurlbert RJ, Arnold P, Oner FC, Harrop $\mathrm{J}$, Anand N: Validating a newly proposed classification system for thoracolumbar spine trauma: Looking to the future of the thoracolumbar injury classification and severity score. $J$ Orthop Trauma 20(8):567-572, 2006

7. Cho SK, Lenke LG, Bolon SM, Pahys JM, Cho W, Kang MM, Zebala LP, Koester LA: Can Intraoperative spinal cord monitoring reliably help prevent paraplegia during PVCR surgery? Spine Deformity 3:73-81, 2015

8. Domanic U, Talu U, Dikici F, Hamzaoglu A: Surgical correction of kyphosis: Posterior total wedge resection osteotomy in 32 patients. Acta Orthop Scand 75(4):449-455, 2004

9. Gaines RW Jr, Carson WL, Satterlee CC, Groh Gl: Experimental evaluation of seven different spinal fracture internal fixation devices using nonfailure stability testing. The load-sharing and unstable mechanism concepts. Spine 16(8):902-911, 1991

10. Garg B, Mehta N: Modified PVCR for severe spinal deformity: A retrospective, comparative study. Spine J 20(9):1446-1451, 2020

11. Gertzbein SD, Harris MB: Wedge osteotomy for the correction of post-traumatic kyphosis. A new technique and a report of three cases. Spine 17:374-379, 1992

12. Gum JL, Lenke LG, Mohapatra A, Sun SQ, Kelly MP: Posterioronly vertebral column resection for fused spondyloptosis. Spine Deformity 6(1):84-95, 2018

13. Hua W, Wu X, Zhang Y, Gao Y, Li S, Wang K, Liu X, Yang S, Yang $\mathrm{C}$ : Incidence and risk factors of neurological complications during PVCR to correct severe posttubercular kyphosis with late-onset neurological deficits: Case series and review of the literature. J Orthop Surg Res 13:269-278, 2018

14. Huang ZF, Chen L, Yang JF, Deng YL, Sui WY, Yang JL: Multimodality intraoperative neuromonitoring in severe thoracic deformity PVCR correction. World Neurosurgery 127: e416-e426, 2019

15. Jo DJ, Kim YS, Kim SM, Kim KT, Seo EM: Clinical and radiological outcomes of modified posterior closing wedge osteotomy for the treatment of posttraumatic thoracolumbar kyphosis. J Neurosurg Spine 23(4):510-517, 2015

16. Kepler CK, Vaccaro AR, Koerner JD, Dvorak MF, Kandziora F, Rajasekaran S, Aarabi B, Vialle LR, Fehlings MG, Schroeder GD, Reinhold M, Schnake KJ, Bellabarba C, Cumhur Oner F: Reliability analysis of the AO Spine thoracolumbar spine injury classification system by a worldwide group of naive spinal surgeons Eur Spine J 25(4):1082-1086, 2016

17. Leatherman KD, Dickson RA: Two-stage corrective surgery for congenital deformities of the spine. J Bone Joint Surg Br 61B:324-328, 1979

18. Lee BH, Hyun SJ, Han S, Kim KJ, Jahng TA, Kim YJ, Kim HJ: Surgical and radiological outcomes after PVCR according to the surgeon's experience. Medicine 97:34(e11660), 2018

19. Lenke LG, O'Leary PT, Bridwell KH, Sides BA, Koester LA, Blanke KM: PVCR for severe pediatric deformity: Minimum two year follow-up of thirty-five consecutive patients. Spine 34:2213-2221, 2009

20. McCormack T, Karaikovic E, Gaines RW Jr: Load sharing classification of the thoracolumbar fractures. Spine 19(16): 1741-1749, 1994 
21. McDonough PW, Davis R, Tribus C, Zdeblick TA: The management of acute thoracolumbar burst fractures with anterior corpectomy and Z-plate fixation. Spine (Phila Pa 1976) 29:1901-1908, 2004

22. Munting E: Surgical treatment of post-traumatic kyphosis in the thoracolumbar spine: Indications and technical aspects. Eur Spine J 19 Suppl 1:69-73, 2010

23. Oner C, Rajasekaran S, Chapman JR, Fehlings MG, Vaccaro AR, Schroeder GD, Sadiqi S, Harrop J: Spine trauma - what are the current controversies? J Orthop Trauma 31 Suppl 4: S1-S6, 2017

24. Ozalay M, Senkoylu A, Benli IT, Uysal M, Derincek A, Altun $\mathrm{N}$ : The results of posterior total wedge osteotomy (Domanic's osteotomy) for coronal and sagittal spinal deformities. J Turk Spinal Surg 19:111-121, 2008

25. Papadopoulos EC, Boachie-Adjei O, Fred Hess F, PerezGrueso FJS, Pellise F, Munish Gupta M, Lonner B, Paonessa $\mathrm{K}$, Faloon $\mathrm{M}$, Cunningham ME, Kim HJ, Mendelow M, Sacramento C, Yazici M; Foundation of Orthopedics and Complex Spine, New York: Early outcomes and complications of PVCR. Spine J 15(5):983-991, 2015

26. Qiu Y, Bangping $Q$, Bin W: Posterior osteotomy for the treatment of thoracic and lumbar fracture delayed postoperative kyphosis curative effect analysis. Chin J Orthop 28:187-191, 2008

27. Roberson JR, Whitesides TE Jr: Surgical reconstruction of late post-traumatic thoracolumbar kyphosis. Spine (Phila Pa 1976) 10:307-312, 1985

28. Saifi C, Laratta JL, Petridis P, JN, Lehman RA, Lenke LG: Vertebral column resection for rigid spinal deformity. Global Spine J 7(3): 280-290, 2017

29. Schoenfeld AJ, Wood KB, Fisher CF, Fehlings M, Oner FC, Bouchard K, Arnold P, Vaccaro AR, Sekhorn L, Harris MB, Bono CM: Posttraumatic kyphosis: Current state of diagnosis and treatment: Results of a multinational survey of spine trauma surgeons. J Spinal Disord Tech 23(7):e1-8, 2010

30. Shimode M, Kojima T, Sowa K: Spinal wedge osteotomy by a single posterior approach for correction of severe and rigid kyphosis or kyphoscoliosis. Spine 27:2260-2267, 2002

31. Shufflebarger HL, Clark CE: Thoracolumbar osteotomy for postsurgical sagittal imbalance. Spine (Phila Pa 1976) 17 Suppl 8:S287-S290, 1992

32. Smith-Paterson M, Larson CB, Aufranc OE: Osteotomy of the spine for correction of flexion deformity in rheumatoid arthritis. J Bone Joint Sur Am 27-A:1-11, 1945

33. Sui WY, Huang ZF, Deng YL, Fan HW, Yang J, Li FB, Yang JL: The safety and efficiency of PVCR without anterior support applied in treatment of Yang's A type severe thoracic kyphoscoliosis. World Neurosurgery 104:723-728, 2017
34. Suk SI, Kim JH, Kim WJ, Lee SM, Chung ER, Nah KH: PVCR for severe spinal deformities. Spine 27:2374-2382, 2002

35. Tang HZ, Xu H, Yao XD, Lin SQ: Single-stage PVCR and internal fixation for old fracture-dislocations of thoracolumbar spine: A case series and systematic review. Eur Spine J 25(8): 2497-2513, 2016

36. Thomasen E: Vertebral osteotomy for correction of kyphosis in ankylosing spondylitis. Clin Orthop Relat Res 194:142-152, 1985

37. Vaccaro AR: Combined anterior and posterior surgery for fractures of the thoracolumbar spine. Instr Course Lect 48:443-449, 1999

38. Vaccaro AR, Lim MR, Hurlbert RJ, Lehman RA Jr, Harrop J, Fisher DC, Dvorak M, Anderson DG, Zeiller SC, Lee JY, Fehlings MG, Oner FC; Spine Trauma Study Group: Surgical decision making for unstable thoracolumbar spine injuries: Results of a consensus panel review by the Spine Trauma Study Group. J Spinal Disord Tech 19(1):1-10, 2006

39. Vaccaro AR, Oner C, Kepler CK, Dvorak M, Schnake K, Bellabarba C, Reinhold M, Aarabi B, Kandziora F, Chapman $J$, Shanmuganathan R, Fehlings $M$, Vialle L; AO Spine Spinal Cord Injury \& Trauma Knowledge Forum: AO Spine thoracolumbar spine injury classification system: Fracture description, neurological status, and key modifiers. Spine (Phila Pa 1976) 38(23):2028-2037, 2013

40. Vaccaro AR, Silber JS: Posttraumatic spinal deformity. Spine 26 Suppl 24:S111-S118, 2001

41. Wang XY, Dai LY, Xu HZ, Chi YL: Kyphosis recurrence after posterior short segment fixation in thoracolumbar burst fractures. J Neurosurg Spine 8(3):246-254, 2008

42. Wang XY, Dai LY, Xu HZ, Chi YL: The load-sharing classification of thoracolumbar fractures: $A n$ in in vitro biomechanical validation. Spine 32(11):1214-1219, 2007

43. Wang Y, Xie J, Zhao Z, Zhang Y, Li T, Bi N, Liu Z, Chen L, Shi Z: Perioperative major non-neurological complications in 105 patients undergoing PVCR procedures for severe rigid deformities. Spine 40(16):1289-1296, 2015

44. Yang C, Zheng Z, Liu H, Wang J, Kim YJ, Cho S: PVCR in spinal deformity: A systematic review. Eur Spine J 25(8):23682375, 2016

45. Yau ACMC, Hsu LCS, O'brien JP, Hodgson AR: Tuberculous kyphosis: Correction with spinal osteotomy, halo-pelvic distraction, and anterior and posterior fusion. $J$ Bone Joint Surg Am 56-A(7):1419-1434, 1974 